DR USHA S. HARRIS is a lecturer at Macquarie University, Sydney

\section{Journalism at the community media level}

Foundations of Community Journalism, edited by Bill Reader and John A. Hatcher. Los Angeles: Sage Publications, 2012, 283 pp. ISBN: 9781412974660 (pbk).

$\mathrm{T}_{\mathrm{a}}$ HIS PUBLICATION adds to a growing body of scholarly work currently being undertaken in the subfield of journalism and mass communication studies known as community media or alternative media. At first glance, the book appears to present a largely American perspective in its coverage of community journalism, but further reading assures one that the editors have fostered an approach that has universal relevance. The term community journalism is broadly defined as 'journalism at the community level'. While the origins of community journalism in the United States is strongly linked to small-town newspapers, the practice has expanded in the 21 st century as the notion of community itself has evolved from its link to geographical ties towards

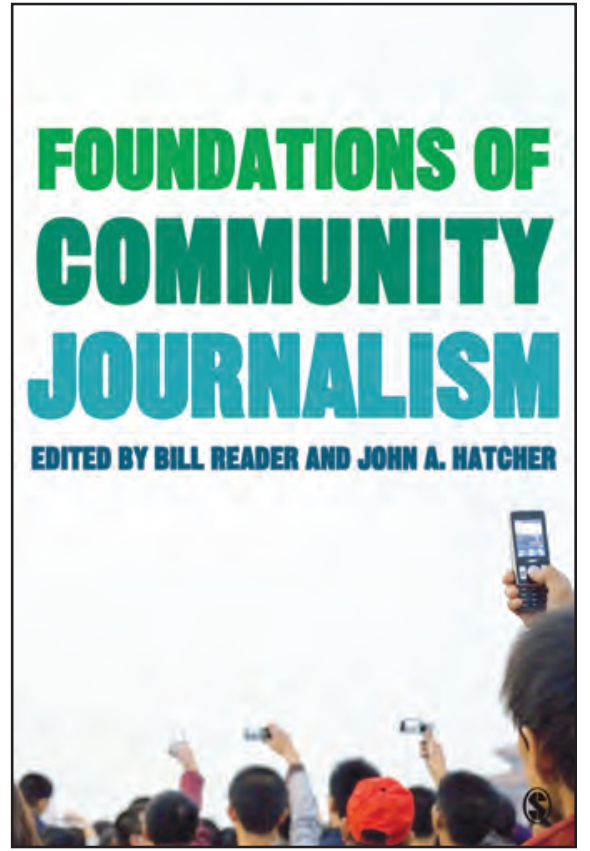

the emergence of global communities linked by ethnicity, religion, culture and interests. This deterritorialisation of community newspapers is demonstrated in the Pacific through the work of Tongan-born publisher Kalafi Moala, who prints weekly editions of Taimi 'o Tonga for distribution to diaspora Tongan communities in New Zealand, Australia and the United States. With the changing conception of community journalism, it has become necessary to study this subfield within broader theoretical approaches, as the editors of this volume reflect in the book's preface, 'to prepare the next generation of scholars for a media environ- 
ment in which community journalism no longer operates in the shadow of 'big J" journalism.' At the end of each chapter the volume includes reflective contributions from scholars and practitioners who bring valuable insights towards enabling a greater theoretical understanding of the field.

There are three parts to the book, each providing a roadmap to conducting research in this field. Part one examines the origins of community journalism within the American context and identifies key works especially establishing connections between local newspapers and different types of community. The section highlights influential research by 'The Minnesota Team' (Phil Tichenor, George Donohue and Clarice Olien) on media-audience interactivity through their study of community newspapers and their local audiences. These researchers found a pattern of consensus rather than conflict in the reporting style of community newspapers which reflected common values and social connections in the community. It led the Minnesota Team to coin the phrase 'Guard Dog', as opposed to the watchdog journalist, because according to the researchers, community journalists appeared to protect the officials and systems in the community in which they worked.
Part two focuses on theories and methods. Chapters in this section provide discussion of interdisciplinary frameworks within which to explore the concept of community journalism. These include the social-scientific methods through a survey of literature of past studies focusing on mediacommunity relationships, critical cultural studies frameworks such as hegemony theory, ritual communication and imagined communities, and the final chapter which turns to political science, geography and sociology to inspire scholars to take up research in the field of community journalism. Crispin Maslog's reflective piece considers the non-Western model of development journalism as a possible parallel to community journalism and civic journalism.

Part three engages in multimedia and global considerations covering broadcasting, online community, magazines as well as the symbiotic relationship between community journalism and public relations and advertising. It was a relief to see inclusion of community radio in the chapter on broadcasting with some good references to recent studies conducted in Australia, Europe, as well as in Nigeria, South Africa, India, Thailand and Brazil. However, the author, George Daniels, questions "whether "community radio" is 
synonymous with "radio community journalism"' (p. 188).

My interest in the final chapter titled 'community journalism as an international phenomenon' was piqued by my own curiosity of how study of community journalism may be framed within a global context. How can a field which is uniquely a product of local community needs have common characteristics around the world? Sure enough, John Hatcher, the author of this chapter, reflects these concerns when he asks 'When we make generalisations about "community journalism," do we risk diluting the very aspect of community journalism that makes it distinct-its cultural relativism?'(p. 243). He observes that there has been 'No attempt to build theory that explains crosscultural variations in community journalism, let alone to position CJ in the current global landcsape' ( $p$. 245). The chapter provides interesting citations of studies and writings that have attempted to fill this gap such as earlier research by Maslog who carried out a comparative study of community journalism in South East Asia as well as country-specific studies in South Africa and Australia. Hatcher provides a useful discussion of possible frameworks within which cross cultural research in CJ could be carried out. In forging the way for future research, Hatcher turns to political scientist, Inglehart's (1997) World Values Survey, Hofstede's (1980) four dimensions of culture, and cross-cultural psychologist, Scwartz's (2004) work on mapping cultural-level values as possible frameworks within which comparative study of community journalism may be undertaken.

While geographic and cultural proximity is a characteristic identified in the definition of community journalism, throughout the book contributors engage with the changing concept of community and how community journalism can be studied in a world where people's networks and community relations transcend physical space. Although written largely from an American experience of community journalism, it nonetheless is worthy of a read by anyone interested in conducting research in community journalism specifically or community media generally. 